\title{
Anosognosia for Behavioral Disturbances in Frontotemporal Dementia and Corticobasal Syndrome: A Voxel-Based Morphometry Study
}

\author{
G. Zamboni ${ }^{a, c}$ J. Grafman ${ }^{a}$ F. Krueger ${ }^{a}$ K.M. Knutson ${ }^{a}$ E.D. Huey a, b \\ ${ }^{a}$ Cognitive Neuroscience Section, NINDS, NIH, Bethesda, Md., and ${ }^{b}$ Litwin-Zucker Research Center for the \\ Study of Alzheimer's Disease and Memory Disorders, Great Neck, N.Y., USA; ' Università di Modena e Reggio Emilia, \\ Modena, Italy
}

\section{Key Words}

Frontotemporal dementia $\cdot$ Corticobasal syndrome .

Voxel-based morphometry · Anosognosia - Loss of insight •

Frontal Systems Behavior Scale

\begin{abstract}
Background: Patients with syndromes of the frontotemporal dementia spectrum are frequently unaware of their behavioral changes. Methods: Seventy patients with a clinical diagnosis of behavioral variant frontotemporal dementia (bv-FTD, $n=27$ ), aphasic variant frontotemporal dementia $(a-F T D, n=12)$ and corticobasal syndrome (CBS, $n=31$ ) participated in the study. Anosognosia for behavioral disturbances was measured as discrepancy between caregiver's and patient's ratings on the Frontal Systems Behavior Scale for present and premorbid behavioral symptoms. Voxelbased morphometry analysis of MRI data was performed to explore the association between anosognosia and gray matter loss. Results: Although behavioral symptoms were reported in all the groups, the comparison between present and premorbid anosognosia revealed that bv-FTD patients not only underestimated their present behavioral disturbances compared to their caregivers, but also overestimated their premorbid behavioral disturbances. Across all groups, the degree of anosognosia for present behavioral impair-
\end{abstract}

ment correlated with gray matter atrophy in a posterior region of the right superior temporal sulcus (adjacent to the temporoparietal junction). Conclusion: These results confirm the role of the right temporoparietal cortex in the genesis of anosognosia and suggest that, in clinical syndromes of the frontotemporal dementia spectrum, anosognosia is associated with the dysfunction of temporoparietal mechanisms of self versus others knowledge.

Copyright $\odot 2010$ S. Karger AG, Basel

\section{Introduction}

Patients with dementia are frequently unaware of their cognitive and behavioral symptoms. In general, the inability to recognize neurological symptoms has been termed as 'loss of insight' $[1,2]$ or 'anosognosia' [3, 4], a term originally used for unawareness of hemiplegia but now adopted to denote the lack of recognition of any disease-specific acquired symptom. Anosognosia for cognitive and behavioral impairment occurring in dementia is clinically relevant and has important consequences on compliance with treatment and caregiver burden [5].

Several studies on patients with Alzheimer disease (AD) have attempted to establish correlations between anosognosia for cognitive symptoms and neuropsycho-

\section{KARGER}

(C) 2010 S. Karger AG, Basel

Fax +41613061234 E-Mail karger@karger.ch www.karger.com
Accessible online at: www.karger.com/dem
Jordan Grafman, PhD, Cognitive Neuroscience Section

National Institute of Neurological Disorders and Stroke

National Institutes of Health, Building 10, Room 7D43; MSC 1440

Bethesda, MD 20892-1440 (USA)

Tel. +1 301496 0220, Fax +1 301480 2909, E-Mail grafmanj@ninds.nih.gov 
logical or demographical variables. Although not consistently, they demonstrated associations with dementia severity [6-8] and neuropsychiatric symptoms such as apathy and depression $[4,9]$. Among the neurodegenerative syndromes of the frontotemporal dementia spectrum, anosognosia has been investigated mainly in the behavioral variant of frontotemporal dementia (bv-FTD) in comparison with AD $[10,11]$. Patients with bv-FTD showed greater anosognosia than patients with $\mathrm{AD}$ and differences were most evident in specific domains such as personality [10], language, executive functions and behavioral disturbances [11]. Limited data are available regarding frequency and characteristics of anosognosia for behavioral disturbances in the aphasic variant (a-FTD) and in other neurodegenerative disorders that share clinical, pathological, and genetic features with FTD, such as the corticobasal syndrome (CBS) $[2,12]$. Moreover, only a few studies have investigated which brain areas are associated with anosognosia in FTD $[1,3]$.

Several studies on patients with stroke and brain injury focused on the neuroanatomical correlates of anosognosia for hemiplegia, showing the predominant role of the right prefrontal and temporoparietal regions $[13,14]$. At the same time, studies on AD patients showed correlations between global anosognosia for cognitive impairment and hypoperfusion of frontal $[7,8,15]$, temporoparietal [4] and temporo-occipital [16] regions. In bv-FTD patients, anosognosia has been correlated with hypoperfusion in the left temporal pole [3] and in right frontal regions [1]. Although there is consensus that anosognosia is symptom specific, there is less agreement on whether certain brain regions have a common role in anosognosia for diverse neurological symptoms [12]. In particular, evidence from studies on brain-injured and dementia patients suggest the association either between anosognosia and the prefrontal cortex, or between anosognosia and the temporoparietal cortex. On one hand, it has been suggested that anosognosia correlates with impairment of executive functions, which are associated - although not exclusively - with the prefrontal cortex [17-19]. In addition, an association between anosognosia and the prefrontal cortex is supported by reports of patients with acquired focal frontal lesions demonstrating lack of awareness and overestimation of abilities [20]. On the other hand, anosognosia has been linked to the temporoparietal cortex because damage to this area of the brain can produce a variety of disorders associated with body knowledge and perception (i.e. somatoparaphrenia and asomatognosia) [21]. In addition, several functional neuroimaging studies have shown that temporoparietal re- gions are part of the network that encompasses representation of the self and others [22]. In particular, right temporoparietal regions are activated when subjects are engaged in tasks in which they have to distinguish between self and others' attributes [22, 23]. Assuming that the self can only be conceptualized in the relationship with others, several authors have suggested that these regions have a general role for self-awareness [24].

The goal of our study was twofold: first, to characterize anosognosia for present and premorbid behavioral dysturbances in bv-FTD patients in which anosognosia has been largely reported, comparing the characteristics of bv-FTD patients with a-FTD and CBS patients who show overlapping symptoms but in whom anosognosia for behavioral disturbances has not been as studied; second, to establish the neuroanatomical correlates of anosognosia for behavioral disturbances and to determine, in patient groups known to have atrophy extending - at different degrees from frontal to temporoparietal areas, whether anosognosia is mainly associated with damage to the prefrontal cortex or temporoparietal regions. We measured anosognosia for behavioral impairment as the discrepancy between patient self-report ratings and ratings provided by caregivers on the Frontal Systems Behavior Scale (FrSBe) [25]. We focused on a measure of behavioral symptoms because these symptoms are easily detected and can occur in all the syndromes of the FTD spectrum including CBS. Then we used voxel-based morphometry (VBM) of MRI data to assess gray matter changes associated with the derived discrepancy score. VBM has been successfully and reliably used to determine correlations between atrophy in specific areas and symptoms in patients with FTD and other types of dementia [26, 27] but - to our knowledge - has never been adopted to study anosognosia in neurodegenerative diseases.

\section{Material and Methods}

\section{Subjects}

Seventy patients with CBS or FTD participated in the study. They were referred by outside neurologists to the Cognitive Neuroscience Section of the National Institute of Neurological Disorders and Stroke (NINDS). During a single 1-week visit to the NIH, patients received extensive clinical and neuropsychological evaluations, and their diagnosis was confirmed according to published criteria $[28,29]$. Inclusion criteria were also the availability of patient's and caregiver's forms of the FrSBe [25]. All patients assigned durable power of attorney prior to enrollment, and assignees gave written informed consent for the study, which was approved by the NINDS Institutional Review Board. Thirty-one patients were characterized clinically as having CBS, 27 as having 
Table 1. Demographics and neuropsychological characteristics of patients and controls

\begin{tabular}{|c|c|c|c|c|c|c|}
\hline $\begin{array}{l}\text { Demographic and behavioral } \\
\text { characteristics }\end{array}$ & Controls & $\begin{array}{l}\text { All } \\
\text { patients }\end{array}$ & $\begin{array}{l}\text { CBS } \\
\text { subgroup }\end{array}$ & $\begin{array}{l}\text { bv-FTD } \\
\text { subgroup }\end{array}$ & $\begin{array}{l}\text { a-FTD } \\
\text { subgroup }\end{array}$ & $\begin{array}{l}\text { Subgroup } \\
\text { comparison }\end{array}$ \\
\hline Number & 14 & 70 & 31 & 27 & 12 & - \\
\hline Gender M:F & $7: 7$ & $36: 34$ & $17: 14$ & $16: 11$ & $3: 9$ & n.s. \\
\hline Age, years & $60.5(1.9)$ & $63.0(1.0)$ & $65.8(1.5)$ & $60.1(1.4)$ & $62.3(2.8)$ & bv-FTD/CBS* \\
\hline Years of education & $16.8(1.0)$ & $15.6(0.3)$ & $14.7(0.5)$ & $16.5(0.6)$ & $16.0(0.4)$ & bv-FTD/CBS* \\
\hline Years since symptom onsets & - & $4.3(0.3)$ & $4.2(0.3)$ & $4.6(0.7)$ & $3.8(0.4)$ & n.s. \\
\hline $\begin{array}{l}\text { FrSBe present discrepancy } \\
\quad \text { (family total - self total score) }\end{array}$ & - & $11.1(3.1)$ & $4.4(3.8)$ & $24.5(5.2)$ & $-1.8(5.6)$ & $\begin{array}{l}\text { bv-FTD/CBS* } \\
\text { bv-FTD/a-FTD* }\end{array}$ \\
\hline $\begin{array}{l}\text { FrSBe retrospective discrepancy } \\
\quad \text { (family total - self total score) }\end{array}$ & - & $-4.0(2.5)$ & $1.7(2.3)$ & $-12.5(4.1)$ & $0.3(8.7)$ & bv-FTD/CBS* \\
\hline Family FrSBe present total score & - & $77.7(2.9)$ & $66.8(3.5)$ & $95.0(3.9)$ & $67.2(7.1)$ & $\begin{array}{l}\text { bv-FTD/CBS }{ }^{* * *} \\
\text { bv-FTD/a-FTD }\end{array}$ \\
\hline Neurobehavioral Rating Scale & - & $46.2(1.2)$ & $45.1(1.9)$ & 46.7 (1.9) & $47.4(2.3)$ & n.s. \\
\hline \multicolumn{7}{|c|}{ MDRS (age-education-matched scaled scores) } \\
\hline normal range & $9.8(0.5)$ & $4.3(0.4)$ & $4.8(0.7)$ & $4.3(0.7)$ & $3.0(0.8)$ & n.s. \\
\hline Beck Depression Inventory & $1.1(0.4)$ & $12.8(1.3)$ & $14.4(2.1)$ & $10.6(1.9)$ & $13.7(2.5)$ & n.s. \\
\hline Wechsler Memory Scale III & - & $87.7(2.2)$ & $92.8(3.2)$ & $83.6(3.4)$ & $82.1(6.3)$ & n.s. \\
\hline Delis-Kaplan Tower Tests & - & $6.8(0.5)$ & $6.5(0.6)$ & $6.3(0.8)$ & $8.2(0.5)$ & n.s. \\
\hline Delis-Kaplan Trial Making & - & $6.2(0.5)$ & $5.5(0.8)$ & $6.5(0.8)$ & $7.3(1.2)$ & n.s. \\
\hline Delis-Kaplan Free Sorting & - & $7.4(0.4)$ & $8.0(0.6)$ & $7.0(0.5)$ & $7.1(0.7)$ & n.s. \\
\hline Delis-Kaplan Category Fluency & - & $5.5(0.4)$ & $6.4(0.7)$ & $5.0(0.7)$ & $4.1(1.2)$ & n.s. \\
\hline Delis-Kaplan Letter Fluency & - & $5.5(0.4)$ & $5.1(0.6)$ & $5.9(0.8)$ & $5.4(1.3)$ & n.s. \\
\hline Token Test & - & $88.8(1.7)$ & $92.0(2.0)$ & $88.7(2.8)$ & $81.2(5.6)$ & n.s. \\
\hline Boston Naming Test & - & $42.9(1.9)$ & $47.6(1.9)$ & $47.3(2.2)$ & $21.2(5.4)$ & $\begin{array}{l}\text { a-FTD/bv-FTD }{ }^{* * *} \\
\text { a-FTD/CBS }\end{array}$ \\
\hline
\end{tabular}

Reported values are means with standard error values in parentheses. The last column on the right reports the results of the comparison (with post hoc Bonferroni-corrected p values) between the 3 patient subgroups; ${ }^{*} \mathrm{p}<0.05,{ }^{* *} \mathrm{p}<0.001,{ }^{* *} \mathrm{p}<0.0005$.

FTD with behavioral presentation (bv-FTD) and 12 as having FTD with aphasic presentation (a-FTD). Out of the 70 patients, 64 (34 women; mean age 62.5 years; mean education 15.4 years; 26 CBS, 26 bv-FTD, and 12 a-FTD) underwent brain MRI, whereas the remaining 6 (5 CBS, 1 bv-FTD) were unable to perform or complete the examination.

For the imaging study, 14 age-matched healthy controls with no history of neurological and psychiatric disorders volunteered to participate in the study. They underwent a neurological examination by NIH staff neurologists, an extensive interview that covered medical, social, familial and psychiatric history and a brain MRI scan. They also received some of the neuropsychological evaluations given to the patients (Mattis Dementia Rating Scale, MDRS; Beck Depression Inventory III) but not those intended to be filled out by caregivers since they had no caregivers. The healthy controls gave informed consent and were paid for their participation. Patients' and controls' characteristics are reported in table 1 .

\section{Neuropsychological Assessment}

Behavioral disturbances were assessed using the FrSBe, which measures behavior before and after the onset of a neurological disorder. The questionnaire is completed by the patient (self-rating form) and by the patient's caregiver (family-rating form).
They have to rate how often the patient has engaged in each of 46 different behaviors (i.e. 'Does things impulsively') on 5-point Likert scales (from 1 = almost never to 5 = almost always). Ratings are collected for 2 points in time: before the illness and at the present time.

To derive a measure of anosognosia, we subtracted the self FrSBe total score from the family FrSBe total score, obtaining a discrepancy score that ranged between negative (caregiver rating the subjects as less impaired in comparison with the subject's selfrating) to positive (caregiver rating the subject as more impaired in comparison with the subject's self-rating). The use of patientcaregiver discrepancy scores as a measure of anosognosia has been reliably adopted in dementia patients $[4,9,11,12]$. Using the standardized FrSBe total scores, discrepancy scores were calculated for the 'before the illness' (retrospective) and 'at the present time' (present) ratings.

As a part of the neuropsychological evaluation, the following tests were also performed: Neurobehavioral Rating Scale; Mattis Dementia Rating Scale, MDRS [30]; Beck Depression Inventory II [31]; Wechsler Memory Scale III [32]; Delis-Kaplan Executive Function System [33]; Token Tests [34], and Boston Naming Test [35]. Among these, age- and education-matched scaled scores of the MDRS, a test of general cognitive function designed for patients with cognitive impairment, were used as measurement of 
dementia severity (scores of $\geq 9$ denote intact cognitive function) and subsequently entered in the VBM analysis.

Demographical and neuropsychological data were analyzed using SPSS 15.0 for PC (SPSS Inc., http://www.spss.com).

\section{Imaging}

MRI images were obtained from a 1.5-tesla GE MRI scanner

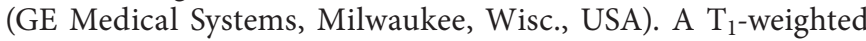
spoiled gradient echo sequence was used to generate 124 contiguous $1.5-\mathrm{mm}$-thick axial slices $(\mathrm{TR}=6.1 \mathrm{~ms}$; $\mathrm{TE}=\mathrm{min}$. full; flip angle $=20^{\circ}$; FOV $=240 \mathrm{~mm}$; matrix size $\left.=256 \times 256 \times 124\right)$.

\section{VBM: Processing and Analysis}

VBM analysis of the data was performed with SPM5 (http:// www.fil.ion.ucl.ac.uk/spm/software/spm5) for Matlab version 7.5.0. Images were registered and segmented using the DARTEL (diffeomorphic anatomical registration through exponentiated lie algebra) algorithm [36], normalized to the Montreal Neurological Institute (MNI) space, and smoothed with an $8-\mathrm{mm}$ FWHM (full width at half maximum) filter. These preprocessing steps were carried out according to the DARTEL chapter of the SPM5 manual (http://www.fil.ion.ucl.ac.uk/spm/\#intro). For the statistical analyses, an absolute threshold mask of 0.05 was used.

To identify gray matter changes correlated with anosognosia for present behavioral abnormalities, the pre-processed (namely, segmented, modulated, normalized and smoothed) images were entered in a correlational analysis (full factorial model) including the diagnostic group (CBS, bv-FTD and a-FTD) as betweengroups factor (independent measurements, equal variance not assumed) and the present FrSBe discrepancy score as covariate of interest. In addition, age, gender, education, total intracranial volume, and dementia severity (MDRS age- and education-matched scaled score) were entered in the model as covariates of no interest. The online supplementary figure 1 (www. karger.com/doi/10.1159/000255141) depicts the final design matrix. This design allowed us to analyze the relationship between anosognosia for present behavioral impairment and gray matter loss in each diagnostic group when assessing the covariate-bygroup interactions separately (i.e. the effect of anosognosia for behavioral impairment in CBS, in bv-FTD and in a-FTD). It also allowed us to analyze the overall effect of anosognosia for present behavioral impairment across all groups, when assessing the relationship in all the 3 groups together. Importantly, all these analyses were performed controlling for the effect of dementia severity, demographical variables and total intracranial volume. Similar 'conditions and covariates' analyses have been previously adopted in studies interested in the correlation between gray matter atrophy and a continuous variable across different diagnostic groups [27]. The relationship between present anosognosia and gray matter atrophy was examined using one-tailed t tests, assuming that increasing severity of anosognosia would be associated with decreased tissue density, although we also tested the opposite relationship as recommended when performing VBM studies [37]. The correlational analysis was performed in the whole brain at the uncorrected statistical threshold of $\mathrm{p}<0.001$, and only results surviving the family-wise error correction for multiple comparisons were considered.

Subsequently, to verify that the correlation between anosognosia for present behavioral impairment and gray matter density was significant in brain areas affected by the illness, we restricted the same correlational analysis to regions of actual atrophy in patients as compared to healthy controls. More precisely, we first performed a full factorial VBM analysis in which we entered each patient group and a group of 14 age- and education-matched healthy controls as separate groups and included age, gender, education and total intracranial volume as confounding covariates. Then we used the regions resulting from the comparisons between each diagnostic group (as well as all groups together) with the control group as a mask for the correlational analysis (online suppl. table 1 for regions of significant difference between all patients and controls)

Identification of brain regions and corresponding Brodmann areas were determined by using anatomical landmarks and by looking at the identified regions in original MNI space projected onto the MRIcron templates [38].

\section{Results}

\section{Demographical and Neuropsychological}

Characteristics

Results from comparison between the diagnostic groups (CBS, bv-FTD and a-FTD) are reported in the last column on the right of table 1 . The groups did not differ significantly in terms of gender and disease duration. There were differences in patient age and years of education, with the bv-FTD patients being significantly younger and less educated than the CBS patients. Therefore, education and age, among other demographical variables, were included as covariates of no interest in the VBM model, allowing us to control for the effects they might have upon anosognosia.

The diagnostic groups did not differ in dementia severity, depression, memory impairment and executive functions. Importantly, the diagnostic groups did not significantly differ in verbal comprehension either (Token Test), confirming that a-FTD patients included in the present study were able to understand the behavioral questionnaires. Instead, as expected, there were differences in oral language production (Boston Naming Test), with a-FTD patients being more impaired than both CBS and bv-FTD patients.

As expected, bv-FTD patients showed more behavioral symptoms measured by the present FrSBe total caregiver form. In particular, post hoc Bonferroni comparisons indicated that bv-FTD patients' FrSBe scores were significantly higher than those of CBS patients and aFTD patients. Note that (although more prominent in bvFTD patients) behavioral symptoms were also reported by caregivers of CBS and a-FTD patients as indicated by the FrSBe total score, which is considered clinically significant if higher than 60-65 [25]. 


\section{Analyses of Retrospective and Present Anosognosia}

Scores

FrSBe retrospective and present discrepancy scores in each diagnostic group measuring of anosognosia for behavioral impairment are also reported in table 1. Negative discrepancy scores meant that caregivers rated patients as less impaired in comparison with patients' selfratings, positive discrepancy scores that caregivers rated patients as more impaired in comparison with patients' self-ratings. There were no significant correlations between the present anosognosia score and scores on neuropsychological tests assessing dementia severity (MDRS, $\mathrm{r}_{70}=0.05$, n.s., one-tailed), overall behavioral impairment (Neurobehavioral Rating Scale, $\mathrm{r}_{70}=0.07$, n.s., one-tailed), language comprehension and production (Token Test, $\mathrm{r}_{69}=0.02$, n.s., one-tailed; Boston Naming Test, $\mathrm{r}_{69}=$ -0.03 , n.s., one-tailed), memory impairment (Wechsler Memory Scale III general memory index score, $\mathrm{r}_{64}=$ -0.19 , n.s., one-tailed) and executive functions (Tower Test, Trial Making Test, Free Sorting, Category and Letter Fluency of the Delis-Kaplan battery, $\mathrm{r}_{\mathrm{s} 70}<0.1$, n.s., onetailed). There was a slightly significant negative correlation with depression severity (Beck Depression Inventory II, $\mathrm{r}_{70}=-0.21, \mathrm{p}=0.037$, one-tailed) indicating that more anosognostic patients tend to be less depressed.

To test whether there is an effect of diagnostic group and time on anosognosia for behavioral impairment, we performed a $2 \cdot 3$ repeated-measures analysis of variance (ANOVA) on the FrSBe discrepancy scores, with time (retrospective and present) as a within-subject factor and diagnostic group (bv-FTD, a-FTD and CBS) as a betweensubject factor. The ANOVA revealed no significant effect of the diagnostic group $\left(\mathrm{F}_{2,67}<1\right.$, n.s.), giving an additional reason for including all 3 patient groups in the same VBM analysis. Instead, there was a significant effect of time $\left(F_{1,67}=30.58, p<0.0005\right)$, indicating that retrospective discrepancy scores were significantly different from present discrepancy scores. The interaction between diagnostic group and time was also significant $\left(\mathrm{F}_{2,67}=35.34, \mathrm{p}<0.0005\right)$, indicating that the retrospective/present directionality of anosognosia scores differed across diagnostic groups. Figure 1 illustrates such a significant interaction. Follow-up 1-way ANOVAs comparing the 3 groups separately in the 2 time points (retrospective and present) showed that the interaction between diagnostic group and time was driven by the bv-FTD group. In the retrospective evaluation, bv-FTD patients showed discrepancy scores that were negative and significantly lower than the discrepancy scores of CBS patients (as shown by post hoc Bonferroni comparisons,

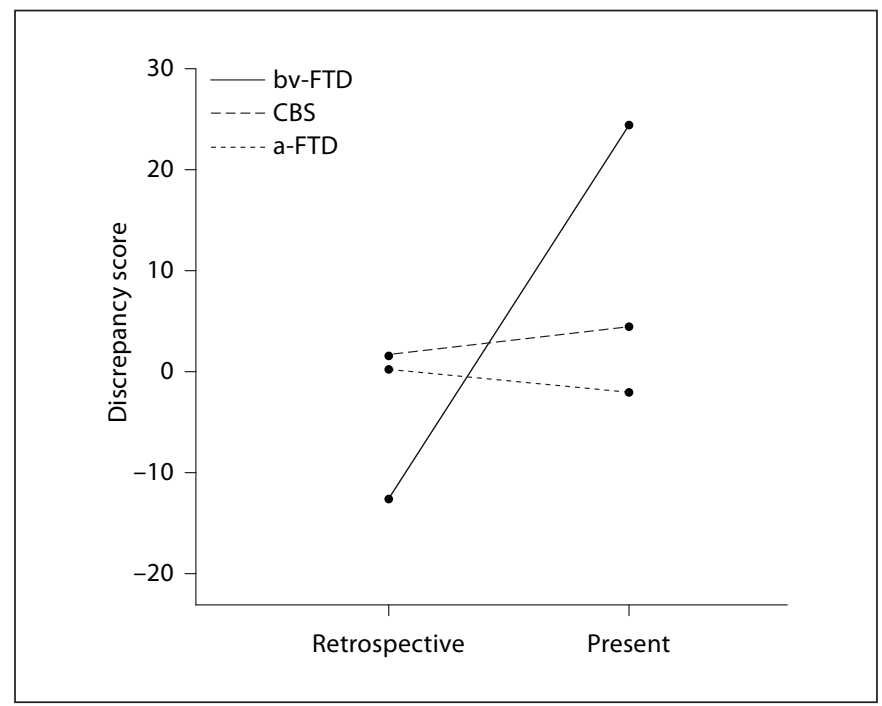

Fig. 1. Retrospective and present anosognosia for behavioral impairment (measured by FrSBe discrepancy scores) as a function of diagnostic group (bv-FTD, a-FTD, CBS). The higher the discrepancy scores, the more anosognosic the patients. In addition, negative scores indicate that caregivers rated the patients as less impaired than patients' self-ratings; positive scores indicate that caregivers rated the patients as more impaired than patients' selfratings. Note that the significant interaction between diagnostic group and time (retrospective, present) is driven by the bv-FTD group.

$\mathrm{p}<0.05)$. In the present evaluation, bv-FTD patients had discrepancy scores that were positive and significantly higher than those of both the a-FTD $(\mathrm{p}<0.05)$ and CBS $(\mathrm{p}<0.05)$ patients (as shown by post hoc Bonferroni comparisons). The bv-FTD group had negative retrospective and positive present discrepancy scores (fig. 1). This means that, in the retrospective evaluation, caregivers rated patients as less impaired than how patients rated themselves ( $t=-3.0$, d.f. $=26, p=0.005$, two-tailed). In the present evaluation, however, caregivers rated patients as more impaired than how patients rated themselves $(\mathrm{t}=4.6$, d.f. $=26, \mathrm{p}<0.0005$, two-tailed). To further explore whether the discrepancy score in bv-FTD was driven by changes in the evaluation of caregivers, patients or both, we performed a follow-up $2 \cdot 2$ ANOVA on the FrSBe total scores (not on the calculated discrepancy) in the bvFTD group, with time (retrospective and present) and rater (patient and caregiver) as within-subject factors. This revealed no significant effect of the rater alone $\left(\mathrm{F}_{1,26}<2\right.$, n.s. $)$, but a significant effect of time $\left(\mathrm{F}_{1,26}=\right.$ $113.65, \mathrm{p}<0.0005)$ and a significant interaction between rater and time $\left(\mathrm{F}_{1,26}=122.16, \mathrm{p}<0.0005\right)$. Therefore, although both patients and caregivers had changed their 
Fig. 2. Regions of reduced gray matter density associated with anosognosia across all diagnostic groups (color online only). Superior temporal sulcus and inferior temporal gyrus as parts of a unique cluster of 1,568 voxels (voxel size $1.6 \cdot 1.6 \cdot 1.8 \mathrm{~mm}^{3}$ ) are visualized at the $\mathrm{p}<0.001$ uncorrected level (for display purposes). The same region also survived the whole-brain familywise-error- and false-discovery-rate-corrected thresholds of $\mathrm{p}<0.05$. Coordinates are in MNI space.

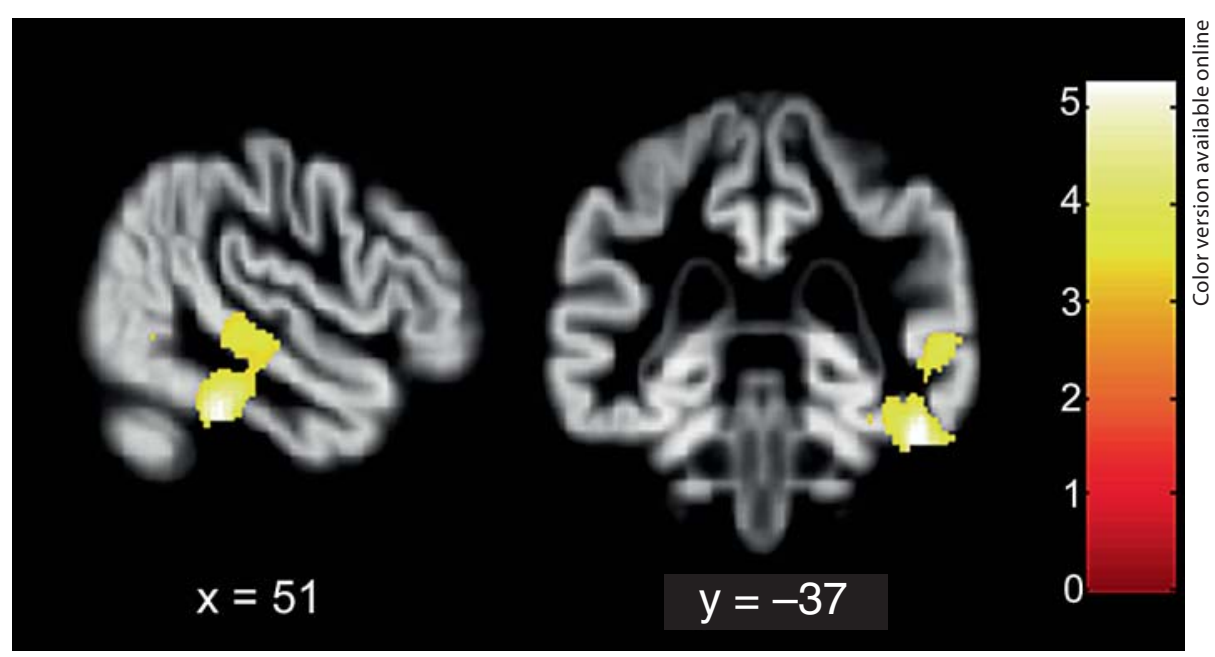

evaluation from retrospective to present as shown by paired $t$ tests between retrospective and present evaluations in caregivers $(t=-14.23$, d.f. $=26, p=0.005$, twotailed) and patients $(t=-3.18$, d.f. $=26, p=0.005$, twotailed), the significant interaction indicated that, as expected in the case of patients unaware of their disturbances, caregivers had changed their judgment more than patients.

\section{VBM Results}

Across diagnostic groups, an increased degree of anosognosia for behavioral impairment was associated with gray matter loss in a single cluster (with 3 peaks) located in the posterior part of the right superior temporal sulcus (pSTS; Brodmann areas 21/39, MNI coordinates of peak voxels: $61,-35,2$ and 59, $-24,-4$; fig. 2), extending inferiorly to the inferior temporal gyrus (ITG; Brodmann area 20; MNI coordinates of peak voxel: $52,-37,-27$; fig. 2). This region survived both the cluster level and the family-wise error voxel level correction for multiple comparisons at $\mathrm{p}<0.05$ (online suppl. fig. 2). When the same analysis was restricted to regions of significant difference between patients and controls, the same region extending from the pSTS to the ITG emerged, confirming that the correlation between atrophy and anosognosia was significant in regions of actual atrophy in the patient groups.

The correlation between gray matter atrophy and anosognosia in each diagnostic group did not show any region surviving correction for multiple comparisons. In addition, there were no regions surviving the cluster or voxel level corrected thresholds in which anosognosia was associated with increased gray matter density.

\section{Discussion}

The present study investigated the characteristics and neural correlates of anosognosia for behavioral symptoms in patients with bv-FTD, a-FTD and CBS. We showed that the caregiver-patient discrepancy was significantly different across the present and retrospective evaluations in the 3 patient groups. In addition, across all patients, increasing anosognosia for behavioral disturbances was associated with gray matter loss in the right posterior temporal lobe.

Behavioral results showed that bv-FTD patients show greater anosognosia for present behavior compared to CBS and a-FTD. Therefore, measuring anosognosia for behavioral disturbances is important for the differential diagnosis of bv-FTD. The presence of behavioral disturbances alone may not be sufficient to distinguish this clinical syndrome from a-FTD and CBS, in which behavioral disturbances may occur as well. This is consistent with previous studies that showed greater anosognosia in bv-FTD compared to a-FTD [12] and AD [10, 11]. Recently, the only study which compared anosognosia in patients with FTD, CBS and progressive supranuclear palsy failed to find significant differences in anosognosia measured with a composite score derived by caregiver-patient comparisons on several questionnaires, including the FrSBe [2]. In that study, FTD patients were more impaired than CBS and progressive supranuclear palsy patients only in the ability to detect cognitive errors. The fact that the authors did not distinguish between behavioral and aphasic presentations of FTD and the different measurement of anosognosia, which included behavioral but also 
cognitive and motor domains, might explain the differences between their results and the results of the present study, in which we focused on anosognosia for behavioral disturbances.

Importantly, discrepancy scores were not significantly associated with dementia severity, overall behavioral impairment or neuropsychological tests assessing specific cognitive domains, including executive functions. This suggests that anosognosia for behavioral disturbances in FTD syndromes can be dissociated from other aspects of cognitive or behavioral impairment. Accordingly, previous studies on FTD patients, although not focused on anosognosia for behavioral disturbances, did not find such an association $[2,11]$.

The comparison between retrospective and present scores revealed - in agreement with previous studies [3, $10]$ - that bv-FTD patients tend to underestimate behavioral changes occurring after the illness onset. Interestingly, we found that in bv-FTD patients the discrepancy from their caregivers' judgment is not only due to underestimation of present behavioral changes, but also to overestimation of previous behavioral disturbances. More precisely, caregivers judged behavioral symptoms before the illness onset lower than the pathological threshold, whereas they judged present behavioral symptoms largely above the pathological threshold. Instead, bv-FTD patients judged their past behavior close to the pathological threshold, and their present behavior as slightly above this threshold, denoting not only the inability to recognize correctly their present behavior, but also the tendency to exaggerate their previous behavior. Therefore, although both caregivers and patients judged present behavioral symptoms more impaired than before the illness, their relationship inverted from the retrospective to the present evaluation. This finding (which was not observed in the a-FTD and CBS groups) cannot be explained by memory impairment, since the diagnostic groups did not differ on neuropsychological evaluation of memory and other cognitive domains such as cognitive functions. The findings of a discrepancy in the assessment of premorbid behavior raises important questions regarding the mechanisms underlying anosognosia in bv-FTD: Does the exaggeration of previous behavioral disturbances indicate that patients confabulate to minimize current behavior abnormalities? Does anosognosia also include a failure of past personal knowledge? Future research is needed to address these questions.

The VBM analysis demonstrated that gray matter loss in a region extending from the right pSTS to the ITG is correlated with increasing anosognosia for behavioral disturbances. The prominent involvement of the temporal lobe differs from previous reports on FTD [1] and AD $[7,8,15]$, in which anosognosia was associated with frontal hypoperfusion. The fact that these analyses were restricted to frontal regions of interest $[7,8]$ or did not include confounding covariates such as dementia severity and demographical differences [15] might account for the differences. In agreement with the present study, other studies conducted on bv-FTD [39] and AD [4] patients, which controlled for the effect of several confounding variables, found that anosognosia measured with patientcaregiver discrepancies is associated with decreased perfusion in temporal regions (temporal pole and temporoparietal junction, respectively). Therefore, although we focused on a specific domain of anosognosia (namely anosognosia for behavioral disturbances), we believe that our results may be generalized to support the hypothesis that the temporoparietal regions, as opposed to frontal regions, are more relevant for anosognosia in FTD and CBS patients. In addition, consistently with previous studies $[13,14]$, our results confirm the predominant role of the right hemisphere in determining anosognosia [40].

A number of functional neuroimaging studies have shown that the right pSTS and the adjacent right temporoparietal junction are associated with a variety of lowlevel and high-level cognitive tasks, from biological motion processing to perspective-taking, from attention reorienting to theory of mind and empathy [for a review, see 41]. In addition, in a VBM study, gray matter loss in the pSTS has been associated with the impaired social abilities observed in autism [42]. These studies have led to the hypothesis that this region is specialized for processing information regarding the mental and emotional states of others and, consequently, for self-awareness [22, 24]. Therefore, our results support the argument that, in dementia patients, anosognosia for behavioral disturbances might be due to their inability to empathically evaluate and understand the others' reaction to their behavior.

We included different diagnostic groups in our VBM analysis that are usually more or less associated with behavioral symptoms. These different disorders are also associated with different patterns of brain atrophy and may present with other symptoms that are usually considered more disease specific (e.g. alien limb in CBS or a naming impairment in a-FTD) than behavioral disturbances. However, the correlational nature of the VBM analysis permits such a grouping, and previous VBM studies have found valid results from performing an analysis of a 
group formed from patients with different diagnoses [27]. The current study showed that patients who are generally unaware of their behavioral impairment have, in pSTS and ITG, greater atrophy relative to patients who are more aware of their behavioral impairment, regardless of the diagnosis, of the overall distribution of atrophy, of the dementia severity and of the potential co-occurrence of other disease-specific symptoms. Further studies are needed to investigate whether these same regions are also associated with anosognosia for more diseasespecific symptoms that may be present in FTD or CBS.

In conclusion, we demonstrated that increasing anosognosia for behavioral impairment is associated with increasing atrophy in a posterior and lateral region of the right temporal lobe including the right superior temporal sulcus/temporoparietal junction. This suggests that, in patients with syndromes of the FTD spectrum, anosognosia for behavioral disurbances may be a consequence of their inability to evaluate the response of others to their own inappropriate behavior, reflecting a dysfunction of basic mechanisms involved in self/others knowledge.

\section{Acknowledgments}

We thank Michael Tierney, Alyson Cavanagh and Karen De Tucci for patient testing, the Clinical Center nurses for patient care, and Nicole Armstrong for assistance with data analysis. This study was supported by the intramural program of the National Institutes of Health/the National Institute of Neurological Disorders and Stroke (to all authors) and the Italian Ministry of University and Research (to G.Z.).

\section{References}

1 Mendez MF, Shapira JS: Loss of insight and functional neuroimaging in frontotemporal dementia. J Neuropsychiatry Clin Neurosci 2005; 17:413-416

2 O'Keeffe FM, Murray B, Coen RF, Dockree PM, Bellgrove MA, Garavan H, Lynch T, Robertson IH: Loss of insight in frontotemporal dementia, corticobasal degeneration and progressive supranuclear palsy. Brain 2007;130:753-764

-3 Ruby P, Schmidt C, Hogge M, D’Argembeau A, Collette F, Salmon E: Social mind representation: where does it fail in frontotemporal dementia? J Cogn Neurosci 2007;19:671683.

-4 Salmon E, Perani D, Herholz K, Marique P, Kalbe E, Holthoff V, Delbeuck X, BeuthienBaumann B, Pelati O, Lespagnard S, Collette F, Garraux G: Neural correlates of anosognosia for cognitive impairment in Alzheimer's disease. Hum Brain Mapping 2006;27: 588-597.

5 Derouesne C, Thibault S, Lagha-Pierucci S, Baudouin-Madec V, Ancri D, Lacomblez L: Decreased awareness of cognitive deficits in patients with mild dementia of the Alzheimer type. Int J Geriatr Psychiatry 1999;14: 1019-1030

-6 Migliorelli R, Teson A, Sabe L, Petracca G, Petracchi M, Leiguarda R, Starkstein SE: Anosognosia in Alzheimer's disease: a study of associated factors. J Neuropsychiatry Clin Neurosci 1995;7:338-344.

7 Reed BR, Jagust WJ, Coulter L: Anosognosia in Alzheimer's disease: relationships to depression, cognitive function, and cerebral perfusion. J Clin Exp Neuropsychol 1993;15: 231-244.
8 Vogel A, Hasselbalch SG, Gade A, Ziebell M, Waldemar G: Cognitive and functional neuroimaging correlate for anosognosia in mild cognitive impairment and Alzheimer's disease. Int J Geriatr Psychiatry 2005;20:238246.

-9 Starkstein SE, Jorge R, Mizrahi R, Robinson RG: A diagnostic formulation for anosognosia in Alzheimer's disease. J Neurol Neurosurg Psychiatry 2006;77:719-725.

10 Rankin KP, Baldwin E, Pace-Savitsky C, Kramer JH, Miller BL: Self awareness and personality change in dementia. J Neurol Neurosurg Psychiatry 2005;76:632-639.

-11 Salmon E, Perani D, Collette F, Feyers D Kalbe E, Holthoff V, Sorbi S, Herholz K: A comparison of unawareness in frontotemporal dementia and Alzheimer's disease. J Neurol Neurosurg Psychiatry 2008;79:176-179.

12 Eslinger PJ, Dennis K, Moore P, Antani S, Hauck R, Grossman M: Metacognitive deficits in frontotemporal dementia. J Neurol Neurosurg Psychiatry 2005;76:1630-1635.

13 Orfei MD, Robinson RG, Prigatano GP, Starkstein S, Rusch N, Bria P, Caltagirone C, Spalletta G: Anosognosia for hemiplegia after stroke is a multifaceted phenomenon: a systematic review of the literature. Brain 2007;130:3075-3090.

14 Pia L, Neppi-Modona M, Ricci R, Berti A: The anatomy of anosognosia for hemiplegia: a meta-analysis. Cortex 2004;40:367-377.

15 Shibata K, Narumoto J, Kitabayashi Y, Ushijima Y, Fukui K: Correlation between anosognosia and regional cerebral blood flow in Alzheimer's disease. Neurosci Lett 2008;435:7-10.
16 Ott BR, Noto RB, Fogel BS: Apathy and loss of insight in Alzheimer's disease: a SPECT imaging study. J Neuropsychiatry Clin Neurosci 1996;8:41-46.

17 Lopez OL, Becker JT, Somsak D, Dew MA, DeKosky ST: Awareness of cognitive deficits and anosognosia in probable Alzheimer's disease. Eur Neurol 1994;34:277-282.

18 Kashiwa Y, Kitabayashi Y, Narumoto J, Nakamura K, Ueda H, Fukui K: Anosognosia in Alzheimer's disease: ASSOCIATION with patient characteristics, psychiatric symptoms and cognitive deficits. Psychiatry Clin Neurosci 2005;59:697-704.

19 Dalla Barba G, Parlato V, Iavarone A, Boller F: Anosognosia, intrusions and 'frontal' functions in Alzheimer's disease and depression. Neuropsychologia 1995;33:247-259.

20 Eslinger PJ, Damasio AR: Severe disturbance of higher cognition after bilateral frontal lobe ablation: patient EVR. Neurology 1985; 35:1731-1741

21 Decety J, Lamm C: The role of the right temporoparietal junction in social interaction: how low-level computational processes contribute to meta-cognition. Neuroscientist 2007:13:580-593.

22 Decety J, Sommerville JA: Shared representations between self and other: a social cognitive neuroscience view. Trends Cogn Sci 2003;7:527-533.

23 Ruby P, Decety J: How would you feel versus how do you think she would feel? A neuroimaging study of perspective-taking with social emotions. J Cogn Neurosci 2004;16:988-999.

24 Blakemore SJ, Frith C: Self-awareness and action. Curr Opin Neurobiol 2003;13:219224. 
25 Grace J, Malloy P: Frontal Systems Behavior Scale (FrSBe): Professional Manual. Lutz, Psychological Assessment Resources, 2001.

-26 Zamboni G, Huey ED, Krueger F, Nichelli PF, Grafman J: Apathy and disinhibition in frontotemporal dementia: insights into their neural correlates. Neurology 2008;71:736742.

-27 Rosen HJ, Allison SC, Schauer GF, GornoTempini ML, Weiner MW, Miller BL: Neuroanatomical correlates of behavioural disorders in dementia. Brain 2005; 128: 2612-2625.

-28 McKhann GM, Albert MS, Grossman M, Miller B, Dickson D, Trojanowski JQ: Clinical and pathological diagnosis of frontotemporal dementia: report of the work group on frontotemporal dementia and Pick's disease. Arch Neurol 2001;58:1803-1809.

29 Boeve BF, Lang AE, Litvan I: Corticobasal degeneration and its relationship to progressive supranuclear palsy and frontotemporal dementia. Ann Neurol 2003;54(suppl 5): S15-S19.

30 Mattis S: Dementia Rating Scale: Professional Manual. Odessa, Psychological Assessment Resources, 1988.
31 Beck AT, Ward CH, Mendelson M, Mock J, Erbaugh J: An inventory for measuring depression. Arch General Psychiatry 1961;4 561-571.

32 Wechsler D: Wechsler Memory Scale, ed 3 (WMS-III). San Antonio, Psychological Corporation, 1997.

33 Delis DC, Kaplan E, Kramer JH: The DelisKaplan Executive Function System: Examiner's Manual. San Antonio, Psychological Corporation, 2001.

34 De Renzi E, Vignolo LA: The token test: a sensitive test to detect receptive disturbances in aphasics. Brain 1962;85:665-678.

35 Kaplan EF, Goodglass H, Weintraub S: The Boston Naming Test. Philadelphia, Lea \& Febiger, 1983.

36 Ashburner J: A fast diffeomorphic image registration algorithm. Neuroimage 2007; 38:95-113.

37 Ridgway GR, Henley SM, Rohrer JD, Scahill RI, Warren JD, Fox NC: Ten simple rules for reporting voxel-based morphometry studies. Neuroimage 2008;40:1429-1435.
8 Rorden C, Brett M: Stereotaxic display of brain lesions. Behav Neurol 2000;12:191200.

-39 Ruby P, Collette F, D’Argembeau A, Peters F, Degueldre C, Balteau E, Luxen A, Maquet P, Salmon E: Perspective taking to assess selfpersonality: what's modified in Alzheimer's disease? Neurobiol Aging 2009;30:16371651.

40 Heilman KM, Barrett AM, Adair JC: Possible mechanisms of anosognosia: a defect in self-awareness. Philos Trans R Soc Lond B Biol Sci 1998;353:1903-1909.

41 Decety J, Moriguchi Y: The empathic brain and its dysfunction in psychiatric populations: implications for intervention across different clinical conditions. Biopsychosoc Med 2007;1:22.

42 Boddaert N, Chabane N, Gervais H, Good $\mathrm{CD}$, Bourgeois M, Plumet MH, Barthelemy C, Mouren MC, Artiges E, Samson Y, Brunelle F, Frackowiak RS, Zilbovicius M: Superior temporal sulcus anatomical abnormalities in childhood autism: a voxel-based morphometry MRI study. Neuroimage 2004; 23:364-369. 